\title{
Contrastive Study of Pragmatic Strategies in the English Speech Act of Requests between Uygur Students and Han Students
}

\author{
Hu Sisi \\ Nanchang Institute of Science \&Technology, Nanchang Jiangxi 330108, China
}

Key words: speech act; requests; pragmatic strategies; Uygur students; Han students.

\begin{abstract}
Based on Searle's speech act theory, Brown \& Levinson's polite theory and interlanguage pragmatic theory, this study makes a contrastive study of pragmatic strategies in English speech act of requests used by Uygur students, Han students and British students by means of a questionnaire. It mainly analyzes the differences between the former two groups of students in the choice of request strategies. The results show that there is a significant difference between Uygur students and Han students in the English speech act of requests, in terms of the use of indirect strategies, since Han students are relatively close to those of British students, while British students are significantly stronger than Uygur students.
\end{abstract}

\section{Introduction}

With the deepening of economic globalization and the increasingly frequent international communication, the language ability plays a more and more important role. Language functions closely related to language forms, which is very significant in the process of learning English. Requests as speech acts are widely used in a variety of situations in our daily life such as asking somebody to shut the door, or asking somebody for a favor. In addition, requests are intrinsically face threatening (Brown \& Levinson, 1987). Therefore, it is of great use and meaning to study the speech act of requests in our daily life, and to study how to avoid or minimize face threatening in realizing a request. If requests are not asked appropriately, the desired goal may not be achieved, and the hearer may feel embarrassed, even the interpersonal relationship may be broken.

Although considerable researches have been done on the speech act of requests either abroad or at home, most of them are mainly focused on the English as a native language and the comparison between English as a native and nonnative languages such as French, German, Chinese, Japanese, Korean, Spanish,etc. Few studies have investigated the pragmatic strategies in English speech act of requests by contrasting two groups of Chinese students, especially minority students and Han students. Thus, the present study aims to do more in-depth studies in this area.

\section{Characteristics of the Speech Act of Requests}

Requests are an especially significant aspect of language because much of what we do in communication revolves around our desire to get someone else to do something (Yang, 2001). Since a request is a speech act that the hearer may feel stressed out for making choices as to meet or deny the request, hence, the speech act of requests is often conveyed by using certain strategies.

In daily communication, people often use two kinds of speech acts, one is direct, the other is indirect. Uyghur language and Chinese have their own unique contexts during the process of using them. Direct speech act refers to express the ideas and opinions in a straightforward way, which is mainly consistent with the speaker's will. That's to say, the speaker can speak frankly and clearly what he wants to say. The use of verbs such as requests, commands, and likes in the Uyghur language and Chinese are listed as follow:

Example 1: Stop playing the game now! 


\section{Example 2: Get up now!}

Example 3: I swear I don't love her anymore!

From the above three examples, the statement of these verbs is used to express the behavior of demand, commitment, guarantee and so on. And we can see that the expressions of these statements are consistent with the potential meaning of the sentences, which are typically the important feature of the direct speech act.

Compared with the direct speech act, indirect speech act tends to be more subtle ways of expression. People do not express their thoughts directly, instead of using some language strategies like asking questions. For example, the following sentence is heard frequently in domestic libraries:

Example 4: Do you still need to read this book?

The speaker who want to read this book will ask whether those people holding the book in hand will read it or not, and for the hearer, these words really mean the request whether the book is worth reading.

And students in domestic often ask questions like this:

Example 5: Do you have a hundred yuan in hand? The meaning of this sentence is to ask if the hearer have one hundred yuan, if he or she has, it is actually asking whether the hearer can lend one hundred yuan to the speaker.

Speech act is one of the classical theories in pragmatics, and many researchers have made a lot of in-depth studies in the field of speech act of requests. Searle (1969) gives the description of a request as a directive speech act which counts as an attempt to get the hearer to do an act which the speaker wants the hearer to do, and which the speaker believes that the hearer is able to do; and which it is not obvious that the hearer will do in the normal course of events or of the hearer's own accord. This notion of an "act" may include the purely verbal acts of giving information, or granting permission.

Generally speaking, three kinds of requests are widely used at the sentential level in most languages. They are: interrogative requests, asking somebody for something in the form of a question; declarative requests, talking about something explicitly in the form of a statement; and imperative requests, directing somebody to do something in the form of a command.

\section{Research Design}

Research Objects. English is the second language for Han students, and the third language for Uygur students, whose second language is Chinese. Since the development of some areas in Uighur are relatively backward, their teaching resources and environment are relatively poor, such cultural differences have resulted in the students' difficulty in learning English, for example, understanding and using the speech act of requests. That's the reason why Chinese is considered to be a prerequisite in the selection of textbooks and outlines in their teaching process.

In this paper, the author compares the pragmatic strategies in English speech act of requests between Uygur students and Han students. 235 non-English major students from freshman to sophomore with approximately equal proportions of Uygur and Han are selected in a university in Jiangxi Province. Uygur students are 100, Han students are 100, 35 foreign students from the United Kingdom are 35. The main objects of the study are the Uygur students and Han students, with relatively same proficiencies in English. The average age of the subjects is 21 years old, and the average time they spent in learning English is 10 years. The basic information of subjects is shown in table 1 . 
Table 1. The General Description of the Subjects

\begin{tabular}{|c|c|c|c|}
\hline \multirow{2}{*}{} & \multicolumn{2}{|c|}{ English learners } & \multirow{2}{*}{ British students } \\
\cline { 2 - 3 } & Uygur students & Han students & \\
\hline Number & 100 & 100 & 35 \\
\hline Age / year & $19-22$ & $18-22$ & $19-24$ \\
\hline Study time / year & 10 & 10 & $19-24$ \\
\hline $\begin{array}{c}\text { Study in English } \\
\text { speaking countries }\end{array}$ & - & - & Long-term \\
\hline
\end{tabular}

Research Methods. The instrument employed in the study is a questionnaire. The selection of topic is close to the real-life environment, including the subway, bus, restaurant, library and other places where requests are commonly needed. The dialogue is not only between teachers and students, but also among students. The setting of the scene is more reasonable, like the subjects' mood, social variables such as distance, power and the level of request, etc. A total of 10 scenario simulation questions are adopted in the questionnaire. The questionnaire was distributed by English teachers in the classroom, the students got 45 minutes to respond.

In order to avoid the wrong judgment of the subjects due to their own limitations, in this paper, the traditional questionnaire and the traditional language supplement test are revised and updated so that the subjects can answer the questions more precisely according to the description of the speech act of requests in different contexts, and eliminate the vague questions and answers. Meanwhile, in view of the fact that British students may have some deviations in understanding the meaning of the context, the questionnaire was made in two versions, the Uygur students and Han students used the Chinese version of the questionnaire, and the British students use the English one.

Data-collection and Data-analysis. During the questionnaire process, the judgement of the answer is mainly based on the score, 1 points for a correct answer, and the full mark is 10 . The data analysis of the questionnaire mainly adopts the coding system of the speech act of requests, which is composed of three kinds of potential language modes. They are the initial behavior, the central behavior and the auxiliary behavior. In the process of testing, the original datas were coded two times. The results show that the consistency is up to $98 \%$. The students' performance of the initial behavior, the central behavior and the auxiliary behavior in the speech act of requests can be seen from table 2.

Table 2. The Different Performance of the Three Groups

\begin{tabular}{|c|c|c|c|}
\hline & Head act & Adjuncts & Total number \\
\hline Uygur students & 71 & 66 & 100 \\
\hline Han students & 68 & 67 & 100 \\
\hline British students & 12 & 15 & 35 \\
\hline
\end{tabular}

\section{Analysis of Research Results}

As shown in Table 3, there are three kinds of strategies used in the investigation of the three groups, which are direct, indirect and a combination of direct and indirect. 
Table 3. The Results of Request Strategies Used in the Three Groups

\begin{tabular}{|c|c|c|c|c|c|c|}
\hline \multirow{2}{*}{} & \multicolumn{2}{|c|}{ Uygur students } & \multicolumn{2}{c|}{ Han students } & \multicolumn{2}{c|}{ British students } \\
\cline { 2 - 7 } & Number & Percentage & Number & Percentage & Number & Percentage \\
\hline Direct & 52 & $52 \%$ & 26 & $26 \%$ & 4 & $12 \%$ \\
\hline Indirect & 30 & $30 \%$ & 50 & $50 \%$ & 21 & $60 \%$ \\
\hline Combination & 18 & $18 \%$ & 24 & $24 \%$ & 10 & $29 \%$ \\
\hline Total & 100 & $100 \%$ & 100 & $100 \%$ & 35 & $100 \%$ \\
\hline
\end{tabular}

According to the results in table 3 , the frequency of indirect strategies used in the three groups of subjects from high to low is: British students (60\%), Han students (50\%) and Uygur students (30\%). The results show that Han students who are in the use of indirect strategies are close to those of British students, while there is a significant difference between Uygur students and British students. As for the direct strategies, the results do reveal significant differences among the three groups. And there is no significant difference in the combination of direct strategies and indirect strategies. That's to say, Han students can use the pragmatic strategies in English speech act of requests more skillfully than the Uygur students and their pragmatic competence tends to be stronger.

\section{Conclusion}

Taking the Uygur students and Han students as the main objects, in this study, the pragmatic strategies in the English speech act of requests have been compared and analyzed. The results indicate that there is a significant difference between Uygur students and Han students in the English speech act of requests. Han students who use the indirect strategies are relatively close to those of British students, but British students are significantly stronger than Uygur students. In the meantime, the results do reveal significant differences among the three groups in the use of direct strategies. And there is no significant difference in the combination of direct strategies and indirect strategies. Therefore, pragmatic strategies in the speech act of requests are more appropriate for Han students than the Uygur students so as to enhance their pragmatic competence in English learning. Like all the studies, the present study also has some limitations and further investigation is still needed to adopt different perspectives and consider using different variables.

\section{Acknowledgement}

The work was supported by the planning project, humanities and social science research project of universities and colleges in Jiangxi with the project number YY161007 and the project name Study on the Influence of Pragmatic Transfer in Third Language Acquisition on Uygur Students' English Speech Acts.

\section{Reference}

[1] Brown, P. and Levinson, S. Politeness: Some Universals in Language Usage [M]. Cambridge: Cambridge University Press, 1987.

[2] Jiang Lili. Cross-cultural Comparison of English and Chinese Request Speech Acts [J]. Literature Education, 2012. 
[3] Jiang Qiyao. A Contrastive Study of the Speech Act of Requests beween Chinese Family and American Family [J]. Times Literature, 2014.

[4] Liu Huiping. A Comparative Study of the Pragmatic Strategies in English Study of English Learners and Chinese Learners [D]. Northeast Normal University, 2012.

[5] Liu Ping. Pragmatic Study of Chinese EFL Learners' Disapproval in Speech Acts [D]. Guangdong University of Foreign Studies, 2006.

[6] Searle, J. Speech Acts [M]. Cambridge: Cambridge University Press, 1969.

[7] Wang Chao, Cao Mei. An Analysis of the Phenomenon of the Uygur Students' Silence in College English Class in Xinjiang [J]. Journal of Xinjiang Vocational University, 2013.

[8] Wang Linhui, Liu Chenyan. A Classroom Teaching Model of Pragmatic Acquisition of Verbal Acts of Demand [J]. Overseas English, 2013.

[9] Yang Chunhong. Chinese Learners’ Realization of Requests in English [M]. Southwest China Normal University, 2001.

[10] Yuan Kunyang. Study on the Cultural Style of Chinese and English Bilinguals' Request Behavior [D]. Shanghai Jiao Tong University, 2013.

[11] Zhang Jie. The Comparison between Chinese and American Speech Acts of Requests in Intercultural Communication [J]. Journal of Minnan Normal University (Philosophy and Social Sciences Edition), 2009.

[12] Zhao Xintong. A Contrastive Study of the Speech Act of Requests between Chinese and Korean [D]. Heilongjiang University, 2014.

[13] Zhang Yuanyuan, Liu Chenyan. Study on College English Request Speech Acts in Pragmatic Failure [J]. Journal of Inner Mongolia Agricultural University (Social Science Edition), 2012. 